\section{References}

1. Cina CS, Althani H, Pasenau J, Abouzahr L. Kommerell's diverticulum and right-sided aortic arch: a cohort study and review of the literature. J Vasc Surg. 2004:39:131-9.

2. Kapustin AJ, Litt HI. Diagnostic imaging for aortic dissection. Semin Thorac Cardiovasc Surg. 2005;17:214-23.

3. Flachskampf FA. Assessment of aortic dissection and hematoma. Semin Cardiothorac Vasc Anesth. 2006;10:83-8.
4. Eltzschig HK, Rosenberger P, Lekowski RW Jr, Scott JD, Locke A, Shekar PS, et al. Role of transesophageal echocardiography in patients with suspected aortic dissection. J Am Soc Echocardiogr. 2005;18: 1221.

5. Ko SF, Ng SH, Fu M, Lo PH, Cheng YF, Lee TY. Dissection of retroesophageal aortic diverticulum and descending aorta in a patient with right aortic arch: magnetic resonance demonstration. Cardiovasc Intervent Radiol. 1996;19:438-41.

\title{
Cardiac pheochromocytoma: A new case reported
}

\author{
Gustavo Knop, MD, ${ }^{a}$ and Roberto Margaria, MD, ${ }^{\mathrm{b}}$ La Pampa, Argentina
}

$\mathrm{P}$ rimary cardiac pheochromocytomas are exceptional. Less than $1 \%$ of these tumors have a thoracic location, being the rarest cardiac occurrence. Thus far, about 50 cases have been reported in the world. We present a case of an intrapericardial tumor that turned out to be a pheochromocytoma in a middle-aged woman.

\section{Clinical Summary}

A 38-year-old woman was referred to a cardiologist at the local hospital because of severe hypertension, paroxysmal episodes of palpitations, headaches, profuse perspiration, and a reddish face.

A transthoracic echocardiogram was performed, and an intrapericardial mass was observed. A coronary angiogram was done and showed the presence of a highly vascularized mass with arterial supply by the circumflex artery (Figure 1). Magnetic resonance imaging confirmed a solid tumor in direct contact with the left atrium and the left superior pulmonary vein. A transesophageal echocardiogram confirmed the location of the mass.

The patient was referred to us for surgical resection of the intrapericardial tumor. At this point, the fact that this tumor was so vascularized raised our clinical suspicion that we might be dealing with a catecholamine-secreting tumor. Laboratory findings of 1100 pg-mL of urine norepinephrine and very high levels of vanillylmandelic acid confirmed that the patient had a pheochromocytoma. Therefore consequently, in the next step of the investigation, we ruled out the classical abdominal location because all the abdominal image studies were negative. A metaiodobenzylguanidine scan study was performed, and the result was not conclusive.

\footnotetext{
From the Department of Cardiovascular Surgery, Argentina Clinic, General Pico, La Pampa, Argentina.

Received for publication June 25, 2006; accepted for publication July 12 , 2006.

Address for reprints: Gustavo Knop, MD, Clinica Argentina, Cirugia Cardiovascular, Av San Martin 730, General Pico, La Pampa 6300, Argentina (E-mail: drknop@hotmail.com)

J Thorac Cardiovasc Surg 2006;132:1230-1

$0022-5223 / \$ 32.00$

Copyright (C) 2006 by The American Association for Thoracic Surgery doi:10.1016/j.jtcvs.2006.07.028
}

A bibliographic revision of cardiac tumors increased our conviction that a car-

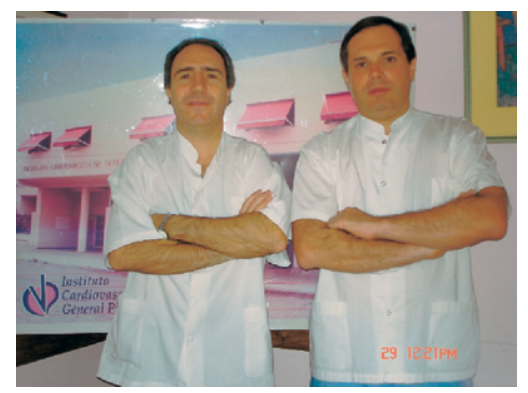

Drs Knop and Margaria (left to right) diac pheochromocytoma, although an extremely rare condition, was present.

After appropriate preoperative preparation of the patient with $\alpha$ - and $\beta$-adrenergic blockers, the operation was performed during cardiopulmonary bypass with bicaval cannulation. Any manipulation of the heart was avoided. The aorta was crossclamped, antegrade cardioplegia was administered, the superior and inferior venae cavae were snared, the right atrium was opened, and the blood and cardioplegia fluid returning from the coronary sinus were sucked and discarded to avoid possible incorporation into the pump circuit of catecholamines released by the tumor and the concomitant occurrence of massive peripheral vasoconstriction. After this precautionary maneuver, our attention was turned to the tumor. A solid and highly vascularized mass 4 by $4 \mathrm{~cm}$ in size (Figure 2) was present on the roof of the left atrium, without a cleavage plane with the left atrial wall and very dense adhesions to the left superior pulmonary vein. The feeding artery of the tumor originating in the circumflex was identified and ligated during the

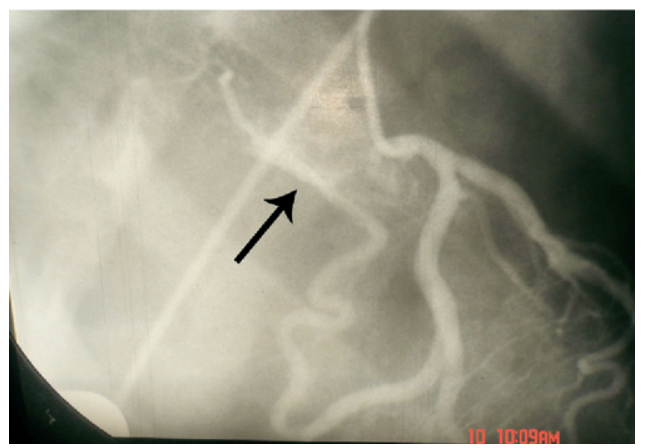

Figure 1. Coronary angiogram showing the arterial supply of the tumor by a significant branch of the circumflex artery and the highly vascularized nature of the catecholamine-secreting tumor. 


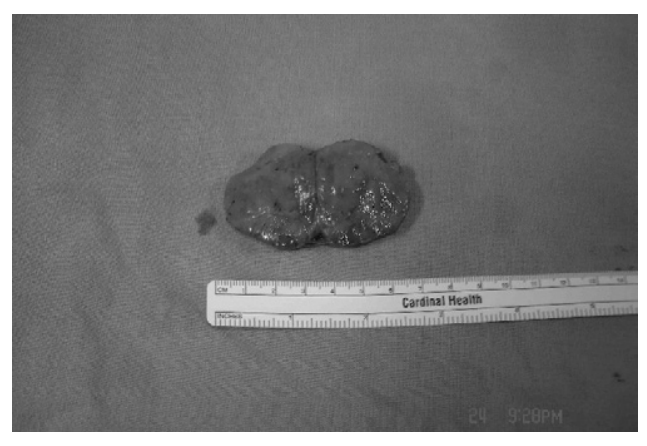

Figure 2. Macroscopic appearance of the cardiac pheochromocytoma.

dissection. Part of the left atrial muscle was resected with the tumor, but no pericardial patches were needed. The next steps of the operation were completed in the usual way, and the patient could be weaned off pump easily. The postoperative course was uneventful.

After 7 months, the patient is asymptomatic and normotensive, and urine catecholamine levels are in the normal range. The histologic examination of the tumor confirmed the diagnosis: a paraganglioma with typical mature pheochromocytes showing marked nuclear and cellular pleomorphism.

\section{Discussion}

Pheochromocytomas are functionally active tumors of the sympathetic nervous system that tend to produce catecholamines, mainly noradrenaline. ${ }^{1}$ The rate of occurrence is rare, with less than $0.1 \%$ of the hypertensive population being affected. ${ }^{2}$

The most usual locations are the adrenal glands in the medulla in $90 \%$ of the cases, where the majority of the chromaffin cells are concentrated. ${ }^{3}$ Small amounts of these cells can exist in the walls of blood vessels, mainly the aorta, and scattered through organs like the ovaries, prostate, and heart. ${ }^{4}$
The diagnosis of these tumors has been difficult to establish. The diagnostic workup includes 2-dimensional and transesophageal echocardiographic studies, ${ }^{5}$ coronary angiography, magnetic resonance imaging, and 131-I-metaiodobenzylguanidine scintigraphy. In the heart most of the tumors reported are intimally associated with the left atrial wall originating from the visceral autonomic paraganglia of the atrium.

The tumor described in this case arose from the superior aspect of the left atrium above the left superior pulmonary vein, being soft and fleshy (Figure 2) and easily compressed, which explains the chance of paroxysmal liberation of catecholamines into the bloodstream.

It was possible to develop a plane of dissection between the atrial wall and the tumor, but this necessitated partial excision of the superficial external aspect of the roof of the left atrium. Adequate preoperative preparation with $\alpha$ - and $\beta$-adrenergic blockers might not prevent serious intraoperative hypertension or high peripheral vascular resistance during cardiopulmonary bypass.

As mentioned above, the histopathology report confirmed the diagnosis of pheochromocytoma.

\section{Conclusions}

Primary cardiac pheochromocytomas are exceptional catecholamine-secreting tumors that present with a variety of symptoms, with severe hypertension being the most significant. Diagnosis and surgical planning are challenging. Surgical excision during cardiopulmonary bypass is the treatment of choice, and cure is the usual result.

\section{References}

1. Jebara VA, Uva MA, Farge A, et al. Cardiac pheochromocytomas. Ann Thorac Surg. 1992;53:356-61.

2. Lee HH, Brenner WI, Vardhan I, Hyatt J, Terlecki M. Cardiac pheochromocytoma originating in the interatrial septum. Chest. 1990;97: 760-2.

3. Orringer MB, Sisson JC, Glazer G, et al. Surgical treatment of cardiac pheochromocytomas. J Thorac Cardiovasc Surg. 1985;89:753-7.

4. Shapiro B, Sisson J, Kalff V, et al. The location of middle mediastinal pheochromocytomas. J Thorac Cardiovasc Surg. 1984;87:814-20.

5. David TE, Lenkei SC, Marquez-Julio A, Goldberg JA, Meldrum DAN. Pheochromocytoma of the heart. Ann Thorac Surg. 1986;41:98-100. 